\title{
Importance of the ultrasound-guided approach for the quadratus lumborum muscle and adjacent structures
}

\author{
Aneiros Zapata A. ${ }^{1}$ Mendoza Rebordinos M.A. ${ }^{1}$ Benito Domingo A. ${ }^{1}$ \\ ${ }^{1}$ Sannus Clinic Medical and Sports Center, Pozuelo de Alarcón, \\ Madrid, Spain \\ Rev Fisioter Invasiva 2019;2:62.
}

\begin{abstract}
Keywords

- quadratus lumborum

- ultrasound-guided approach

- invasive physical therapy

- musculoskeletal ultrasound
\end{abstract}

Introduction Ultrasound is currently a powerful and valuable tool for assessment purposes and for the performance of invasive procedures during physical therapy treatments, to the extent that this technology is becoming essential for many of these techniques. The evolution undergone by ultrasound-guided techniques in our profession derives in the need to research the importance of the combined use of these two powerful tools.

Aims To demonstrate the importance of ultrasound guidance for the treatment of the quadratus lumborum muscle and adjacent structures.

Material and Methods 20 volunteer subjects were evaluated (seven women and 13 men) aged 22 to 54 years who were asymptomatic. Four freehand approaches were performed (two freehand approaches, one approach on acupuncture point V52 and one approach described by Travell and Simons) and two ultrasound-guided approaches (in prone and in side lying). Each approach was performed twice by the same physical therapist. The freehand approaches were performed by two physical therapists with over five years' experience in invasive physical therapy techniques. The assessment and post-intervention measurements were performed by another physical therapist with over five years' experience in ultrasound assessment and invasive physical therapy techniques. Ultrasound-guided approaches were performed by a physical therapist with over five years' experience in invasive techniques and ultrasound assessment. The data were analyzed with SPSS statistical software for Windows.

Results Statistically significant differences were found between the freehand approaches and ultrasound guided approaches regarding the ability to reach the objective/target tissue (17.5\% hit ratios compared to $100 \%$ ), obtaining a mean distance in the failed attempts of $0.5165 \mathrm{~cm}(0.11-1.61 \mathrm{~cm})$. In $70 \%$ of the freehand approaches the needle was found in the iliocostal muscle. Overall, during the freehand approaches, and without considering the learning effect, the percentages of hits on the target decreased (from $17.5 \%$ to $11.25 \%$ ) and the percentage needle placements on the iliocostal increased (from 70\% to 75\%).

Conclusions During physical therapy procedures of the quadratus lumborum muscle and peripheral structures ultrasound-guided approaches are essential to reach the target tissue effectively and with safety.
DOI https://doi.org/ 10.1055/s-0039-3401853. ISSN 2386-4591.
Copyright @ 2019 by Thieme Revinter

Publicações Ltda, Rio de Janeiro, Brazil
License terms

(c) (1) $\odot$ (\$) 